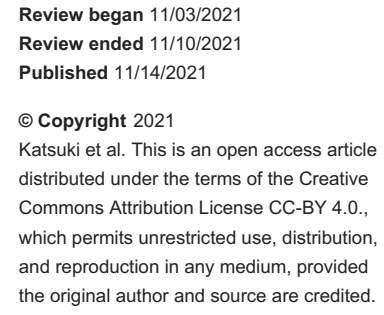

\title{
Homonymous Hemianopsia Due to the Infarction in the Splenium of the Corpus Callosum
}

\author{
Masahito Katsuki $^{1,2}$, Hideaki Kato ${ }^{1}$, Hiroshi Niizuma ${ }^{1}$, Yoichi Nakagawa ${ }^{3}$, Masahiro Tsunoda ${ }^{4}$ \\ 1. Neurosurgery, Senseki Hospital, Higashi-Matsushima, JPN 2. Neurosurgery, Itoigawa General Hospital, Itoigawa, \\ JPN 3. Ophthalmology, Nakagawa Eye Clinic, Ishinomaki, JPN 4. Ophthalmology, Tsunoda Ganka, Wakuya-cho, JPN
}

Corresponding author: Masahito Katsuki, ktk1122nigt@gmail.com

\begin{abstract}
The precise functions of the splenium of the corpus callosum (CC) remain unclear, and infarction of this location manifests varied clinical symptoms. We describe a rare case of right homonymous hemianopsia resulting from pure infarction in the right-side splenium of the CC. An 85-year-old man presented with right homonymous hemianopsia lasting for a week. Diffusion-weighted imaging showed a high-intensity area in the right-side splenium of the CC and did not show any other lesions in other portions of the visual pathways. Magnetic resonance angiography demonstrated anterior and posterior cerebral arteries, indicating that no large vessel occlusion existed. The visual field examination revealed right homonymous hemianopsia. The diagnosis was atherothrombotic infarction in the splenium of the CC, which resulted in right homonymous hemianopsia. Two months later, T2-weighted imaging showed a high-intensity lesion localizing the right-side splenium with shrinkage of the lesion compared to that on the acute phase, and his visual field was slightly improved. There are few reports on the splenial infarction of the $\mathrm{CC}$, and this is the first case manifesting as homonymous hemianopsia, to our knowledge. Our case might help to understand complicated visual information processing involving the splenium of the CC.
\end{abstract}

Categories: Neurology, Ophthalmology, Neurosurgery

Keywords: atherosclerosis, visual information processing, hemianopsia, cerebral infarction, splenium

\section{Introduction}

The corpus callosum (CC) is the biggest commissural fibrous bundle of the central nervous system and divided into four parts: the rostrum, genu, body, and splenium. The splenium is the thickest part of the CC, and the majority of the fibers extend posteriorly into the occipital lobes [1]. Infarctions of the CC are rare because of their abundant collateral blood supply from the anterior and posterior circulation through pericallosal anastomotic plexus [2]. The most common location of the CC infarction is the splenium [2]. However, clinical symptoms of the splenial lesion are variable, such as cognitive impairment, aphasia, and alien hand syndrome, and precise functions of the splenium remain unclear [3,4]. We herein describe a rare case of right homonymous hemianopsia due to splenial infarction of the CC. To our knowledge, this is the first case with right homonymous hemianopsia resulting from the splenial infarction of the CC.

\section{Case Presentation}

An 85-year-old right-handed man was referred for right homonymous hemianopsia lasting for a week by his ophthalmologist treating his glaucoma. He did not have any lifestyle-related diseases and take any medicines. The laboratory tests on admission revealed serum triglyceride level $133 \mathrm{mg} / \mathrm{dL}$, high-density lipoprotein cholesterol level $32 \mathrm{mg} / \mathrm{dL}$, low-density lipoprotein cholesterol level $59 \mathrm{mg} / \mathrm{dL}$, glucose level 188 $\mathrm{mg} / \mathrm{dL}$, hemoglobin A1c level 6.4\%, and other items were all within normal limits. He had habitual smoking and drinking. The Holter electrocardiogram did not find atrial fibrillation.

Diffusion-weighted imaging showed a high-intensity lesion mainly in the right-side splenium of the CC but the lesion extended to the contralateral side. No lesions were found in other portions of the visual pathways (Figure 1A-1D). The lesion was also evident on the T2-weighted imaging (T2WI) (Figure 1E). The magnetic resonance angiography revealed mild atherosclerosis (Figure $1 F$ ). The diagnosis was atherothrombotic infarction in the splenium of the CC, which resulted in right homonymous hemianopsia, and cilostazol was prescribed. 


\section{Cureus}
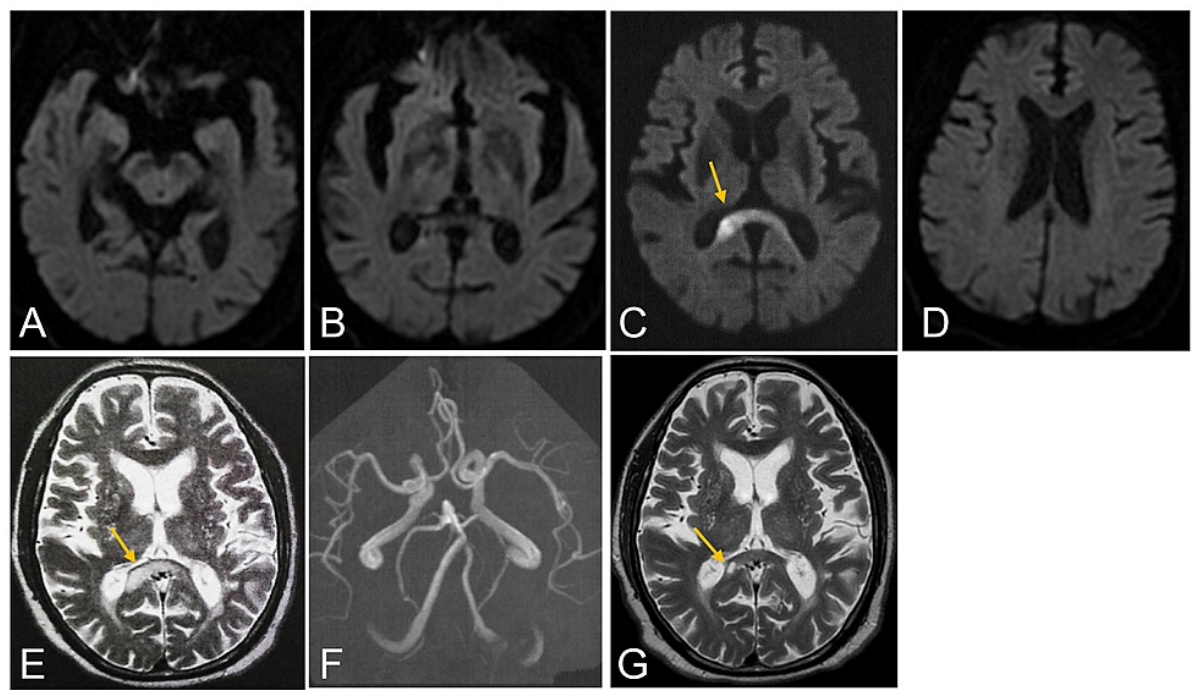

\section{FIGURE 1: Magnetic resonance imaging}

Diffusion-weighted imaging on admission showed a high-intensity lesion spreading from the right-side splenium of the corpus callosum to the contralateral side (arrow in C), but did not show any other lesions in other portions of the visual pathways (A, B, D). T2-weighted imaging on admission showed the same finding (arrow in E). The magnetic resonance angiography revealed mild atherosclerosis $(F)$. Two months later, T2-weighted imaging showed a high-intensity lesion, which became localized to the right-side splenium of the CC (arrow in G)

The visual field examination on day 13 confirmed irregular pattern of visual field narrowing and defects, which is considered as a combination of right homonymous hemianopsia due to splenial infarction and visual field narrowing due to glaucoma (Figure 2A). No other ophthalmologic diseases were found. Two months later, the high-intensity lesion on T2WI significantly shrank and became localized to the small area of the right-side splenium of the CC (Figure 1G). The visual field examination confirmed an improvement of his homonymous hemianopsia (Figure $2 B$ ). 


\section{Cureus}
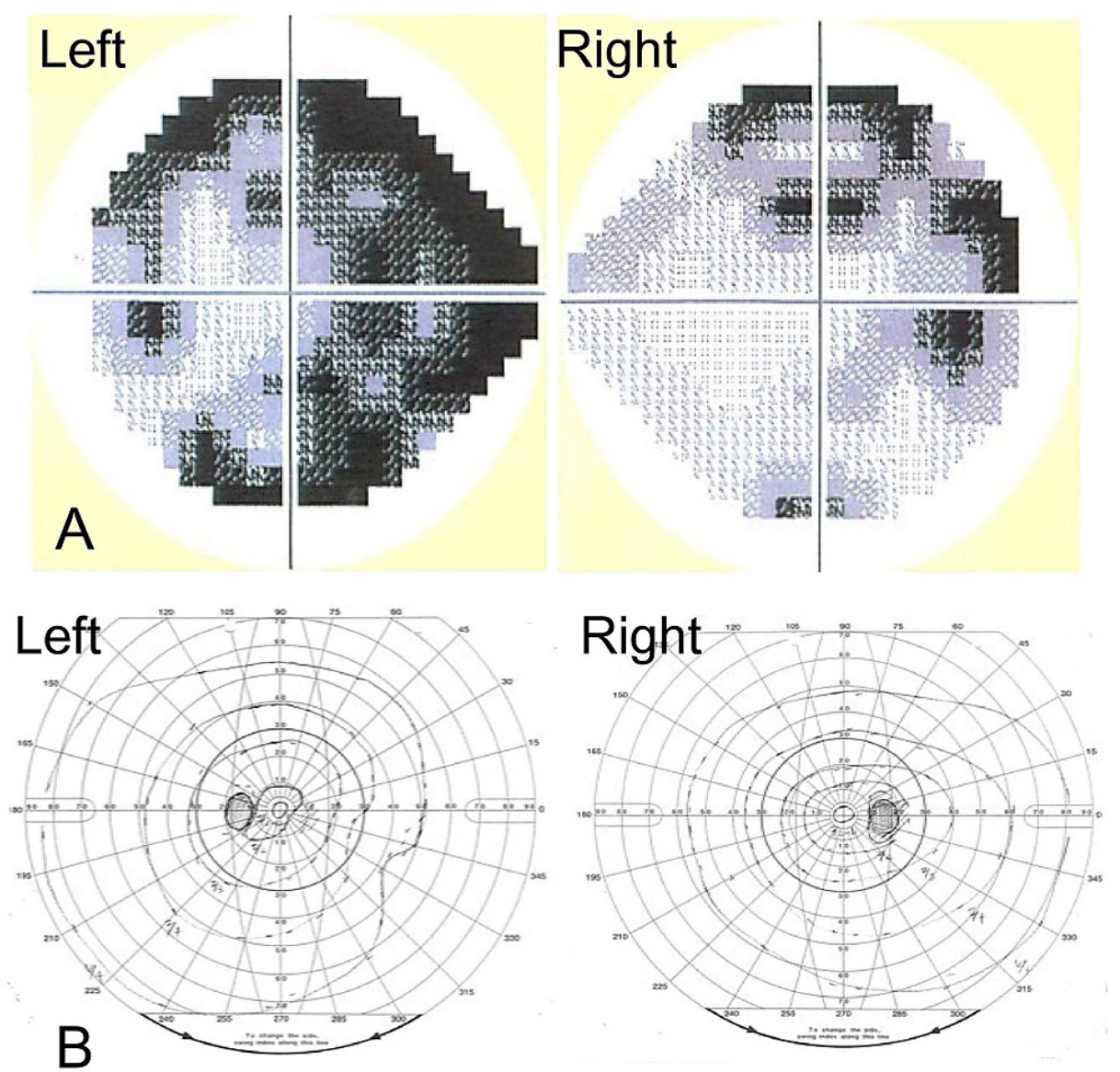

\section{FIGURE 2: Visual field examination}

The visual field examination by an ophthalmologist on day 13 confirmed right homonymous hemianopsia with visual field narrowing due to glaucoma (A). The visual field examination 2 months later showed an improvement of his right homonymous hemianopsia $(\mathrm{B})$.

\section{Discussion}

The visual pathway refers to the series of cells and synapses, which transmit visual signals from the environment to the brain for processing. This pathway begins with light striking the specialized nerve cells of the retina. It converts photons of light into electrochemical signals. The neural signals are transferred through the retinal layers to the optic nerve, optic chiasm, optic tract, lateral geniculate body, optic radiation, and visual cortex in the brain's occipital lobe [5]. Each optic tract classically carries the contralateral half of the visual field, so the lesions on the optic tract, lateral geniculate body, optic radiation, and visual cortex result in homonymous hemianopsia. The primary cause of the homonymous hemianopsia is stroke (70\%), and around $80 \%$ of its responsible lesions locate in the occipital lobes or the optic radiations [6]. However, our case had the right homonymous hemianopsia resulting from the splenial infarction with the intact optic tract, optic radiations, and occipital lobes.

The most common location of CC infarction is the splenium, but pure splenial infarction is rare. Because of the well-developed collateral circulation, CC infarction usually accompanies with additional lesion due to large vessel occlusion [2,7]. Therefore, there have been only 10 previous reports of pure splenium infarction $[3,8-16]$ without any other lesions in the cortex nor optic tract (Table 1). No cases had homonymous hemianopsia, but four cases had metamorphopsia. Saito et al. hypothesized that the visual information would be processed in the bilateral temporal, parietal, and occipital lobes across the hemispheres and that metamorphopsia was caused by a disrupted transfer of visual information at the splenium and the major forceps [10]. Similarly, we hypothesized that right homonymous hemianopsia was caused by an interrupted transfer of visual information at the splenium of the CC across the hemispheres [17]. In other words, visibility would not be defined only in the unilateral striate cortex, but also in the bilateral cortexes across the hemispheres. However, this theory cannot explain the laterality. Further studies, including tractography and functional imaging, are expected. 


\section{Cureus}

\begin{tabular}{|c|c|c|c|c|c|c|c|}
\hline Author & Year & Age & Sex & Laterality & Neurological symptoms & Etiology & Prognosis \\
\hline Hashiguchi et al. [8] & 2009 & 63 & $\mathrm{M}$ & $\mathrm{L}$ & $\begin{array}{l}\text { Loss of motivation, dysarthria, } \\
\text { memory disturbance }\end{array}$ & ATBI & $\begin{array}{l}\text { Not improved in } 14 \\
\text { days }\end{array}$ \\
\hline Katsura et al. [9] & 2010 & 67 & $\mathrm{~F}$ & L & Right-sided metamorphopsia & ATBI & $\begin{array}{l}\text { Not improved in } 20 \\
\text { days }\end{array}$ \\
\hline Saito et al. [10] & 2014 & 61 & $\mathrm{~F}$ & $\mathrm{R}$ & Left-sided metamorphopsia & ATBI & $\begin{array}{l}\text { Not improved in } \\
2.5 \text { years }\end{array}$ \\
\hline Nagaishi et al. [11] & 2015 & 78 & $\mathrm{~F}$ & $\mathrm{R}$ & Left-sided metamorphopsia & ATBI & $\begin{array}{l}\text { Improved in } 18 \\
\text { days }\end{array}$ \\
\hline \multirow[t]{2}{*}{ Chang and Huang [12] } & 2015 & 57 & ? & $\mathrm{R}$ & Hemiparesis, dysarthria & ATBI & Unknown \\
\hline & & 43 & ? & L & Dizziness, memory disturbance & ATBI & Unknown \\
\hline \multirow[t]{3}{*}{ Li et al. [3] } & 2015 & 78 & $\mathrm{M}$ & $\mathrm{L}$ & Hemiparesis, dysarthria & Undetermined & Unknown \\
\hline & & 74 & $\mathrm{~F}$ & $\mathrm{~L}$ & Hemiparesis, ataxia, hypesthesia & ATBI & Unknown \\
\hline & & 61 & $\mathrm{~F}$ & Bilateral & $\begin{array}{l}\text { Headache, vertigo, disturbance of } \\
\text { consciousness }\end{array}$ & ATBI & Coma \\
\hline Lai and Katirji [15] & 2017 & 21 & $\mathrm{~F}$ & Center & Photophobia & $\begin{array}{l}\text { Cerebral venous } \\
\text { thrombosis }\end{array}$ & $\begin{array}{l}\text { Improved in few } \\
\text { days }\end{array}$ \\
\hline Zhu et al. [13] & 2018 & 53 & $\mathrm{M}$ & $\mathrm{R}$ & Left-hand weakness & ACA dissection & Unknown \\
\hline $\begin{array}{l}\text { Barghouthi and El } \\
\text { Husseini [16] }\end{array}$ & 2018 & 67 & $\mathrm{~F}$ & L & Prosopometamorphopsia & Undetermined & Improved in a year \\
\hline \multirow[t]{3}{*}{ Zhang et al. [14] } & 2019 & 53 & $\mathrm{M}$ & $\mathrm{R}$ & Unknown & ACA dissection & Unknown \\
\hline & & 57 & $\mathrm{~F}$ & $\mathrm{R}$ & Dizziness & ATBI & Unknown \\
\hline & & \multicolumn{4}{|c|}{ Four others (not described) } & & \\
\hline Our Case & 2019 & 85 & M & $\mathrm{R}$ & Right homonymous hemianopsia & $A|B|$ & $\begin{array}{l}\text { Slightly improved } \\
\text { in } 14 \text { days }\end{array}$ \\
\hline
\end{tabular}

\section{TABLE 1: Previous reports on pure infarction in the splenium of corpus callosum}

ACA: anterior cerebral artery; ATBI: atherothrombotic cerebral infarction

\section{Conclusions}

We described a case with right homonymous hemianopsia resulting from the splenial infarction of the CC. We hypothesized that right homonymous hemianopsia was caused by an interrupted transfer of visual information at the splenium of the CC across the hemispheres. In other words, we hypothesized that the visibility would not be defined only in the unilateral striate cortex, but also in the bilateral cortexes across the hemispheres. Our case might help to understand complicated visual information processing involving the splenium of the CC. Further studies, including tractography and functional imaging, are expected.

\section{Additional Information}

\section{Disclosures}

Human subjects: Consent was obtained or waived by all participants in this study. Itoigawa General Hospital Ethics Committee issued approval 2021-4. Our hospital's research ethics committee approved the study, and we gained written informed consent for this study from the patient. All methods were carried out under relevant guidelines and regulations (Declaration of Helsinki). All personal patient information was deleted from the database for this study to protect patient privacy. Conflicts of interest: In compliance with the ICMJE uniform disclosure form, all authors declare the following: Payment/services info: All authors have declared that no financial support was received from any organization for the submitted work.

Financial relationships: All authors have declared that they have no financial relationships at present or within the previous three years with any organizations that might have an interest in the submitted work. Other relationships: All authors have declared that there are no other relationships or activities that could appear to have influenced the submitted work. 


\section{References}

1. Musiek FE: Neuroanatomy, neurophysiology, and central auditory assessment. Part III: Corpus callosum and efferent pathways. Ear Hear. 1986, 7:349-58. 10.1097/00003446-198612000-00001

2. Kontzialis M, Soares BP, Huisman TA: Lesions in the splenium of the corpus callosum on MRI in children: a review. J Neuroimaging. 2017, 27:549-61. 10.1111/jon.12455

3. Li S, Sun X, Bai YM, et al.: Infarction of the corpus callosum: a retrospective clinical investigation . PLoS One. 2015, 10:e0120409. 10.1371/journal.pone.0120409

4. Yang LL, Huang YN, Cui ZT: Clinical features of acute corpus callosum infarction patients . Int J Clin Exp Pathol. 2014, 7:5160-4.

5. Mehra D, Moshirfar M: Neuroanatomy, Optic Tract. StatPearls [Internet]. StatPearls Publishing, Treasure Island, FL; 2021.

6. Zhang X, Kedar S, Lynn MJ, Newman NJ, Biousse V: Homonymous hemianopias: clinical-anatomic correlations in 904 cases. Neurology. 2006, 66:906-10. 10.1212/01.wnl.0000203913.12088.93

7. Yamaguchi Y, Iwasaki Y, Wada M, Makita N, Nagasawa H, Yamakawa T, Toyoda K: Transient lesion of the splenium of the corpus callosum after acute ischemic stroke. Intern Med. 2019, 58:1011-5. 10.2169/internalmedicine.1010-18

8. Hashiguchi A, Yano S, Nitta K, Ide W, Hashimoto I, Kamada H, Kuratsu J: Hemisplenial- accompanied by internal border-zone infarction: clinical relevance of the splenium of the corpus callosum as a border-zone area between anterior and posterior cerebral arteries. J Neurol Neurosurg Psychiatry. 2010, 81:704-6. 10.1136/jnnp.2009.173468

9. Katsura K, Konno K, Yamagata M: A case of corpus callosum infarction with unilateral facial metamorphopsia (Japanese). J Japanese Soc Intern Med. 2010, 99:1318-20. 10.2169/naika.99.1318

10. Saito Y, Matsunaga A, Yamamura O, Ikawa M, Hamano T, Yoneda M: [A case of left hemi-facial metamorphopsia induced by infarction of the right side of the splenium of the corpus callosum]. Rinsho Shinkeigaku. 2014, 54:637-42. 10.5692/clinicalneurol.54.637

11. Nagaishi A, Narita T, Gondo Y, Nakane S, Fukudome T, Matsuo H: [Left-sided metamorphopsia of the face and simple objects caused by an infarction at the right side of the splenium of the corpus callosum]. Rinsho Shinkeigaku. 2015, 55:465-71. 10.5692/clinicalneurol.cn-000666

12. Chang TP, Huang CF: Unilateral paresthesia after isolated infarct of the splenium: case report . Acta Neurol Taiwan. 2010, 19:116-9.

13. Zhu X, Zhang X, Lu S, Liu Z: Rare etiology for splenium of corpus callosum infarction: anterior cerebral artery dissecting aneurysm. Neurology. 2018, 91:481-2. 10.1212/WNL.0000000000006133

14. Zhang Z, Meng X, Liu W, Liu Z: Clinical features, etiology, and 6-month prognosis of isolated corpus callosum infarction. Biomed Res Int. 2019, 2019:9458039. 10.1155/2019/9458039

15. Lai W, Katirji B: Splenium infarct due to cerebral venous thrombosis . Arch Neurol. 2007, 64:1540. 10.1001/archneur.64.10.1540

16. Barghouthi T, El Husseini N: Prosopometamorphopsia secondary to a left splenium of the corpus callosum infarct. BMJ Case Rep. 2018, 2018:bcr-2018-224735. 10.1136/bcr-2018-224735

17. Jang SH, Lee HD: Recovery of visual field defect via corpus callosum in a patient with cerebral infarct . Neuroophthalmology. 2015, 39:88-91. 10.3109/01658107.2014.998771 